\title{
CARACTERIZACIÓN MICROESTRUCTURAL DE MEZCLAS DESHIDRATADAS DE POLISACÁRIDOS-PROTEÍNAS POR MICROSCOPIA DE FUERZA ATÓMICA
}

\section{Carmen Carla Quiroga Ledezma}

\section{RESUMEN}

Las microestructuras de mezclas de amilosa - $\beta$-lactoglobulina (AM- $\beta \lg$ ) y amilopectina - patatina (AP-PA), formadas a partir de la deshidratación de soluciones de diferentes concentraciones y diferentes relaciones polisacárido:proteína, se estudiaron usando Microscopía de Fuerza Atómica (Atomic Force Microscopy - AFM). Los resultados se confirmaron por Microscopia de Transmisión Electrónica (Transmission Electron Microscopy - TEM). Los compuestos puros mostraron estructuras lisas, aunque entre los polisacáridos, la amilosa tuvo una estructura más rugosa, y entre las proteínas la patatina. Las proteínas naturales mostraron diferentes estructuras en comparación con las proteínas tratadas térmicamente, que mostraron estructuras rugosas, resultado de la agregación de sus moléculas. Los sistemas polisacáridos-proteínas mostraron estructuras que no sufrieron una segregación de fases a relaciones polisacárido:proteína igual a 1:1 para la AM:ßlg y mayores a 1:1 para AP:PA, y que sufrieron una segregación de fases a relaciones menores a 1:1 para AM: $\beta$-lg e iguales o mayores a 1:1 para AP:PA. Las muestras con segregación de fases presentaron regiones ricas en polisacárido y regiones ricas en proteína. Después del tratamiento térmico las muestras que no mostraron una segregación de fases presentaron algún grado de segregación, el grado de segregación de fases estuvo en función de la concentración de proteína.

Palabras Clave: Separación de Fases, Segregación de Fases, Películas Deshidratadas, Microscopia de Fuerza Atómica, $\beta$-Lactoglobulina, Amilopectina, Patatina 